\title{
Self-Efficacy Training Improved The Quality of Life for Cancer Patients Undergoing Chemotherapy
}

\author{
Agustina Boru Gultom ${ }^{1}$ \& Indrawati ${ }^{1}$ \\ ${ }^{1}$ Health Polytechnic, Health Ministry Medan, North Sumatera, Indonesia \\ Correspondence: Agustina Boru Gultom, Health Polytechnic, Health Ministry Medan, North Sumatera, Indonesia. \\ E-mail: agustinagultom203@gmail.com
}

Received: February 10, 2020 Accepted: March 21, 2020 Online Published: March 30, 2020

doi:10.5539/gjhs.v12n4p118 URL: https://doi.org/10.5539/gjhs.v12n4p118

\begin{abstract}
The survival of cancer patients is often short despite receiving therapy, but it really depends on various things including those that play an important role is the ability of patients to improve their life status in dealing with illnesses and therapy through increased self-efficacy because self-efficacy of cancer patients often experience reduction due to cancer and the therapy it undergoes. The pre-test and the first post -test and also the second post-test research design in the form of self-efficacy training of cancer patients undergoing chemotherapy used a quasi-experimental design without a control group. Data analysis used dependent t test and repeat ANOVA test. There were significant effects and differences in self-efficacy training on the quality of life of cancer patients undergoing chemotherapy with the $\mathrm{p}$ value dependent test was 0,000 and the repeat ANOVA test was $p$ value 0,000 . The uses of structured self-efficacy training be one of the considerations of nursing interventions to improve the quality of life of cancer patients undergoing chemotherapy.
\end{abstract}

Keywords: self-efficacy training, quality of life

\section{Introduction}

Cancer is a problem that is of concern to the world because it is the second leading cause of death. Cancer is estimated to be responsible for 9,6 million deaths in the world in 2018, where cancer causes 1 in 6 deaths worldwide (WHO, 2018). The percentage of patient survival after being diagnosed with cancer is usually within 5 years. The proportion of patients recovering from cancer deaths also occurs after 5 years after the diagnosis is established. However, this depends on how the individual interprets the cause of cancer because each patient will experience sophistication in the detection and treatment of different, factors that cause a patient to survive from cancer such as treatment itself, comorbidities, behavioral differences, and biological differences and screening earlier than cancer is experienced (American Cancer Society, 2017).

Cancer therapy with chemotherapy used in some affected patients is the first alternative as a therapy to overcome the cancer that is experienced. Chemotherapy as a therapy in treating cancer has the goal of therapy to eradicate cancer cells, control the enlargement of the cancer so that it does not spread and to reduce the symptoms caused by cancer. Chemotherapy has the nature of working throughout the body, which differs in the way it works with radiation therapy or surgery (Junaidi, 2007; Arruebo et al., 2011).

Patients who have just been diagnosed with cancer will ask about how long they will live, how they can be cured, hair loss. Cancer patients who, without being given training, must make medical decisions in a state of being experiencing fear, pressure and high vulnerability (Leigh \& Stovall, 2012). After the patient faces chemotherapy, he will ask about whether there is still a chance to be cured, if it cannot be cured, how long will it live, will it be better or worse, is there any benefit in taking chemotherapy treatment, can it live long with chemotherapy, is there anything other things that can be done (Harrington \& Smith, 2008; Bronner et al., 2017). Patients will pay attention to the body's symptoms that occur and must learn in dealing with unknown situations by asking about how many times I have to check myself, are there any symptoms that arise, is this normal, why do I feel fatigue or fear and faces hopes for a future that is not clear. In this condition, the quality of life of cancer patients is an important concern (Leigh \& Stovall, 2012).

Patients who have been diagnosed with cancer will face unequal adaptations in dealing with chemotherapy and the side effects obtained when using chemotherapy. The side effects vary including physical side effects and 
psychological side effects (Lavdaniti,2015). Eventually, patients who face chemotherapy will experience a decrease in quality of life (Perwitasari, 2009). Chemotherapy has a close relationship in shaping the quality of one's life (Massoni et al., 2015). Quality of life is a state of individual life which is confronted with several aspects which as a whole are in a prosperous condition. Quality of life has a meaning that is in line with the notion of health (Juczynki, 2006). According to WHO, quality of life or health consists of welfare in the physical, psychological and social fields where it is not just the absence of disease or weakness (WHO, 2008).

Self-efficacy in cancer patients following the therapy that they undergo will experience varying levels of carrying out their duties in controlling the problems that occur (Foster et al., 2015). Self-efficacy is a belief that determines how a person thinks, motivates himself and how finally he decides to do a behavior to achieve the desired goal (Bandura (1997) in Snyder \& Lopez, 2002; Williams \& Rhodes, 2016). From a study it was found that low self-efficacy often occurs in women, experiencing higher pain and depression, lack of quality of life scores, low socioeconomic status, lack of social support and have more negative perceptions about cancer (Foster et al., 2015).

Self-efficacy in dealing with cancer is an ability that is done to overcome the stress experienced by cancer patients who have good self-efficacy will be easier to deal with life lived and the lack of negative psychological impacts that occur and improve quality of life. (Chirico et al., 2017). The positive or negative moods of individuals who will shape their efficacy in several studies are influenced by several neurotransmitters that exist in the brain's limbic system. One of them is endorphins. The endorphin hormone is a neurotransmitter that will be released into the body when individuals are in a state of excitement with laughter, love, when listening to music or in a calm state such as during meditation. When endorphins are released into the body a lot, then the individual will have a high positive mood with him self. (Dfarhud et al., 2014).

The low self-efficacy of cancer patients undergoing chemotherapy causes a decrease in the quality of life. For this reason, efforts are needed to improve self-efficacy through training in the form of group intervention support. Supporting short-term group interventions in cancer patients, such as providing information, emotional and social support, stress management, relaxation techniques will improve psychological well-being, reduce anxiety and depression, increase self-confidence in overcoming problems and quality of life. (Weis, 2003; Foster et al., 2015; $\mathrm{Hu}, 2017)$. One's self-efficacy is developed through four main sources, namely the esperience of success, the experience of others, social persuasion and physical and emotional conditions. Experience of success is gained through direct experience and achievements in the past. While the experience of others is gained through the use of social models by means of observation. Social persuasion is obtained through suggestion or acceptance of suggestions to be able to overcome problems, as well as physiological and emotional states obtained through situations created to influence physiologically and emotionally (Bandura in Snyder \& Lopez, 2002). The aim of the study was to analyze the effect of self-efficacy training on the quality of life of cancer patients undergoing chemotherapy. In this study, only the experimental group received self-efficacy training. Before intervention, a pre-test was done then the next day followed by self-efficacy training for 2 days plus a post-test, and at 4 weeks later a post test was conducted again. The problem can be formulated: "How was the effect of self-efficacy training on the quality of life of cancer patients undergoing chemotherapy". The hypothesis of this study was that there was an effect of self-efficacy training on the quality of life of cancer patients undergoing chemotherapy.

\section{Method}

A quantitative study using a quasi-experimental design without a control group was conducted at the Dr. Pirngadi General Hospital Medan, Indonesia from July to October 2019. The population were all cancer patients undergoing chemotherapy. Sample size was measured using the hypothesis test formula for the proportion of a single population of 48 respondents. The sampling technique was consecutive sampling with sample were as follows, adult patients with minimal cancer are undergoing second chemotherapy, ECOG Performance Status $<4$, have full awareness and did not experience disorientation in place, time and people, can communicate using good Indonesian, are willing to be respondents and follow the research procedures until the final stage.

Respondents were divided into 10 groups, where 1 group consisted 4-5 respondents ( 8 groups of 5 respondents, 2 group of 4 respondents). On the second day to the third day, each group will experience self-efficacy training within 2 days assisted with a training module where day 1 was 2 hours long, and day 2 is 2,5 hours, 2 hours exercise and the first post test 0,5 hours. After 4 weeks, in the fifth week, respondents in each group received a second post-test with the same questionnaire.

Self-efficacy training was development of bandura theory combined with nursing and health theories. On the first day, the theme of self-efficacy training included theme 1 regarding experiences of success including definition, sources, benefits and development of efficacy in daily life, theme 2 on social persuasion was how motivation and social support, theme 3 on physical and emotional conditions included managing stress, recognize tense areas and 
visualization. On the second day, the theme included theme 1 about the the expereince of success of others was modeling of people who recovered from cancer, theme 2 about physical and emotional conditions was a progressive muscle relaxation exercise accompanied by classical music, theme 3 about social persuasion was setting future goals.

The research variable was self-efficacy, namely the patient's belief in thinking, in motivating himself and deciding the role, emotional function, cognitive function, and social function as well as the symptoms that occur were measured by the Cancer Behavior Inventory-B self-efficacy questionnaire with interval measuring scale $12-108$, Quality of life which was a condition of the individual's life conditions which is confronted with several aspects of the individual's personal life as a whole in a prosperous condition measured by the FACT-G Version- 4 quality of life questionnaire with interval measuring scale 0-108. Data anayzed using paired $t$ test and repeated ANOVA test. This study was approved by the ethics commission of the Health Ministry of Health Polytechnic,Medan,number 261/KEPK POLTEKKES KEMENKES MEDAN/2019.

\section{Results}

\subsection{Univariate Analysis}

\section{Characteristics of Respondents}

Characteristics of respondents in this study include age, sex, marital status, income, occupation, education, cancer diagnosis, duration of cancer and ECOG can be seen in Table 1.

Table 1. Distribution of Respondent Characteristics.

\begin{tabular}{lcc}
\hline Variable & Frequency & Total (\%) \\
\hline Age & 3 & $6,3 \%$ \\
$20-34$ & 10 & $20,8 \%$ \\
$35-44$ & 30 & $62,5 \%$ \\
$45-59$ & 4 & $8,3 \%$ \\
$60-74$ & 1 & $2,1 \%$ \\
$75-90$ & 48 & $100,0 \%$ \\
\hline Total & & \\
\hline Gender & 14 & $29,2 \%$ \\
Male & 34 & $70,8 \%$ \\
Female & 48 & $100,0 \%$ \\
\hline Total & & \\
\hline Marital Status & 1 & $2,1 \%$ \\
Single & 44 & $91,7 \%$ \\
Married & 3 & $6,3 \%$ \\
Widower/widow & 48 & $100,0 \%$ \\
\hline Total & & \\
\hline Income & 18 & $12,5 \%$ \\
$>$ Rp. 4.500 .000 & 2 & $35,4 \%$ \\
$\geq$ Rp. $2.132 .188-4.500 .000$ & 17 & $52,1 \%$ \\
$<$ Rp. 2.132 .188 & 25 & $100,0 \%$ \\
\hline Total & 48 & \\
\hline Type of Work & & \\
Housewife & $25 \%$ \\
Private Employees & & \\
\hline & & \\
\hline
\end{tabular}




\begin{tabular}{|c|c|c|}
\hline Civil Servants/State-Owned Enterprises & 4 & $8,2 \%$ \\
\hline Entrepreneur & 3 & $6,3 \%$ \\
\hline Retired & 3 & $6,3 \%$ \\
\hline Etc & 18 & $37,5 \%$ \\
\hline Total & 48 & $100,0 \%$ \\
\hline \multicolumn{3}{|l|}{ Education } \\
\hline Elementary School & 12 & $25,0 \%$ \\
\hline Middle School & 5 & $10,4 \%$ \\
\hline High School & 25 & $52,1 \%$ \\
\hline College & 6 & $12,5 \%$ \\
\hline Total & 48 & $100,0 \%$ \\
\hline \multicolumn{3}{|l|}{ Cancer Diagnosis } \\
\hline Breast Cancer & 22 & $45,8 \%$ \\
\hline Lung Cancer & 3 & $6,3 \%$ \\
\hline Ovarian Cancer & 5 & $10,4 \%$ \\
\hline Uterine Cancer & 2 & $4,2 \%$ \\
\hline Penile Cancer & 3 & $6,3 \%$ \\
\hline Rectal Cancer & 3 & $6,3 \%$ \\
\hline Testicular Cancer & 2 & $4,2 \%$ \\
\hline Colon Cancer & 5 & $10,4 \%$ \\
\hline Lymph Node Cancer & 2 & $4,2 \%$ \\
\hline Cervical Cancer & 1 & $2,1 \%$ \\
\hline Total & 48 & $100,0 \%$ \\
\hline \multicolumn{3}{|l|}{ Long Suffered From Cancer } \\
\hline$<1$ Year & 26 & $54,2 \%$ \\
\hline$\geq 1-<5$ Year & 20 & $41,7 \%$ \\
\hline$\geq 5-<10$ Year & 2 & $4,2 \%$ \\
\hline Total & 48 & $100,0 \%$ \\
\hline \multicolumn{3}{|l|}{$\underline{\mathrm{ECOG}}$} \\
\hline 1 & 16 & $33,3 \%$ \\
\hline$\underline{2}$ & 27 & $56,3 \%$ \\
\hline$\underline{3}$ & 5 & $10,4 \%$ \\
\hline Total & 48 & $100,0 \%$ \\
\hline
\end{tabular}

\section{Self Efficacy}

The results of this study have described the minimum score, maximum, mean and standard deviation of self-efficacy, can be seen in Table 2 . 
Table 2. Minimum Score, Maximum, Mean and Standard Deviation of Self-Efficacy

\begin{tabular}{lccccc}
\hline Type & N & Min & Max & Mean & SD \\
\hline Pre self-efficacy score & 48 & 33 & 96 & 54,75 & 13,73 \\
Post self-efficacy Score 1 & 48 & 40 & 100 & 64,73 & 12,98 \\
Post self-efficacy Score 2 & 48 & 43 & 103 & 73,60 & 12,36 \\
\hline
\end{tabular}

\section{Quality of Life}

The results of this study have described the minimum score, maximum, mean and standard deviation of quality of life, can be seen in Table 3.

Table 3. Minimum Score, Maximum, Mean and Standard Deviation of Quality of Life

\begin{tabular}{lllllc}
\hline Type & N & Min & Max & Mean & SD \\
\hline Pre Quality of Life Score & 48 & 29 & 93 & 59,62 & 14,53 \\
\hline Post Quality of Life Score 1 & 48 & 53 & 94 & 70,17 & 10,51 \\
\hline Post Quality of Life Score 2 & 48 & 56 & 98 & 76,52 & 11,26 \\
\hline
\end{tabular}

\subsection{Bivariate Analysis}

Bivariate analysis in this study was about the effect of self-efficacy training on the quality of life of cancer patients undergoing chemotherapy. To analyze the effect before and after the training was given, a $t$ dependent test was performed with a significance level $(\alpha)=0,05$ if the data was normally distributed, or wilcoxon test with significance level $(\alpha)=0,05$ if the data were not normally distributed. From the results of the normality test with Shapiro-Wilk obtained pre, post-1 and post-2 self efficacy variables were not normally distributed, while the pre, post-1, post-2 quality of life variables were normally distributed.

After the normality test was carried out, the correlation test was carried out and followed by a test of the effect before and after the self-efficacy training on the quality of life of cancer patients undergoing chemotherapy according to the results of the normality test. The result can be seen in Table 4 and Table 5 .

Table 4. Correlation of Self Efficacy With Quality of Life In Cancer Patients Undergoing Chemotherapy

\begin{tabular}{lcc}
\hline Correlation & $\boldsymbol{P}$ & $\boldsymbol{R}$ \\
\hline Correlation of pre self-efficacy with pre quality of life & 0,000 & 0,491 \\
\hline Correlation of post-1 self-efficacy with post-1 quality of life & 0,000 & 0,600 \\
\hline Correlation of post-2 self-efficacy with post-2 quality of life & 0,000 & 0,624 \\
\hline
\end{tabular}

Table 5. The Effect of Self-Efficacy Training on The Quality of Life of Cancer Patients Undergoing Chemotherapy

\begin{tabular}{|c|c|c|c|}
\hline \multirow{2}{*}{ Influence } & Mean & Standard & \multirow{2}{*}{$p$} \\
\hline & Differences & Deviation & \\
\hline The effect of self efficacy before the intervention and after the intervention & 9,98 & 0,69 & 0,000 \\
\hline The effect of self-efficacy after the intervention and after 4 weeks & 8,88 & 5,54 & 0,000 \\
\hline Influence of quality of life before the intervention and after the intervention & 10,54 & 8,30 & 0,000 \\
\hline Influence of quality of life after the intervention and after 4 weeks & 6,35 & 5,43 & 0,000 \\
\hline
\end{tabular}

To carry out the comparative hypothesis of numerical variables of more than two groups, was there a difference between the three measures of self-efficacy and quality of life both before training, after training and 4 weeks after 
training, then Repeated ANOVA test if the data was normally distributed and Friedman test if the data was not normally distributed. The results ofvariables showed that there were significant differences in self-efficacy score before, after and 4 weeks after self efficacy training using the Friedman test with p 0,000, there were significant differences in the quality of life score before, after and 4 weeks after self-efficacy training using repeated ANOVA test with $\mathrm{p} 0,000$.

\section{Discussion}

The purpose of this study was to analyze the effect of self-efficacy training on the quality of life of cancer patients undergoing chemotherapy. In this study, self-efficacy training in cancer patients undergoing chemotherapy was designed as an effort to improve quality of life. The findings can be summarized in the statistical test data of this study showing that self-efficacy training in cancer patients undergoing chemotherapy can improve quality of life.

From the results of the study showed the majority of cancer respondents undergoing chemotherapy aged

45-59 years, female, married, low income, housewife and other occupations or non-permanent jobs, having a high school education, the diagnosis of breast cancer, length of suffer $<1$ year, and ECOG 2 .

The patients included in this study partially experienced a decrease in self-efficacy which displayed an efficacy score before self-efficacy training of $(54,75 \pm 13,73)$. Several studies have shown that self-efficacy in cancer patients was low.(Lev,1999; Curtis et al,2014). After an attempt was made on the patient, self-efficacy increased $(64,73 \pm 12,98)$. Four weeks after efforts were made to the patient, the patient's self-efficacy increased by $(73,60 \pm 12,36)$. Cancer patients will experience high fear, pressure and vulnerability without training or information (Leigh \& Stovall,2012). Without efforts to increase the self-efficacy given to cancer patients, the patient's self-efficacy will decrease. (Lev et al., 1999; Lu et al., 2017).

The results of the study showed that there was a relationship between self-efficacy and the quality of life of cancer patients who underwent chemotherapy before self-efficacy training with $\mathrm{p} 0,000$ having moderate relationship strength $(\mathrm{r}=0,491)$, after training with $\mathrm{p} 0,000$ having strong relationship strength $(\mathrm{r}=0,600)$, after 4 weeks training with $\mathrm{p} 0,000$ has the strength of strong relationship $(\mathrm{r}=0,624)$. Several studies have suggested that there was a strong relationship between self-efficacy and quality of life in cancer patients and the therapy they undergo (Chirico, 2017; Omran \& Mcmillan,2018). The results of the study also showed that the mean difference in self-efficacy scores before the intervention and after the intervention was $(9,98 \pm 0,69)$ and there was an effect of self-efficacy training on the self-efficacy of cancer patients undergoing chemotherapy with a $p$ value of $0,000<$ 0,05 . The mean difference in self-efficacy score after intervention and after 4 weeks of intervention was $(8,88 \pm 5,54)$ and there was an effect of self-efficacy training on the self-efficacy of cancer patients undergoing chemotherapy after 4 weeks of self-efficacy training with $p$ value $0,000<0,05$. The study results also showed a significant difference between the three measurements of self-efficacy both pre,post-1,post- 2 with a $p$ value of $0,000<0,05$.

Self-efficacy is an essensial essence for a human being in living his life, in forming proper behavior, healthy and prosperous. It's role is also very important in controlling the conditions of life that must be faced. Self-efficacy does not come suddenly, but must continue to be built and developed. Development through four ways includes the experience of success, the experience of others, social persuasion and the creation of physical and emotional conditions (Bandura in Snyder \& Lopez, 2002; Hoffman, 2013). Self-efficacy is an important component in cancer patients. Based on that the condition can be a trigger factor or a factor that reduces the occurrence of cancer (Lev, 1999; Cunningham, 1991; Chirico et al., 2017). Patients who are diagnosed with cancer will be faced with the actions that they will receive and this will have an effect on their self-efficacy (Mystakidou et al., 2012; Akin, 2008).

Patients in this study partially experienced a decrease in quality of life with an average score of $(59,63 \pm 14,53)$, and when viewed from each dimension also partially decreased as physical dimensions with an average score $(15,81 \pm 5,50)$, dimensions of social/family relationships with an average score $(16,75 \pm 4,41)$, dimensions of feeling conditions with an average score $(14,27 \pm 4,84)$, and dimensions of functional conditions with an average score $(13,21 \pm 4,19)$.

Several studies have shown that quality of life in cancer patients was low.(Nayak et al., 2017; Driessen et al., 2012). Low quality of life will be displayed by a decrease in physical conditions, poor social/family relationships, unstable mood conditions, and functional conditions in living everyday life and at work becomes low.

After efforts were made to the patient, the quality of life of the patient increased with an average score of $(70,17 \pm 10,51)$, and also increased if described from each dimension also increased. 
Cancer patients who undergo chemotherapy will experience changes in their life status.(Iconomou et al., 2004). Efforts to improve the quality of life in cancer patients undergoing chemotherapy are efforts that must be done continuously. Cancer will have a decreased impact on immune power, while chemotherapy undertaken as a treatment can also damage normal cells in the patient's body. Self-efficacy is one of the factors related to quality of life. (Meifen et al., 2015; Foster et al., 2015).

The results of the study showed the difference in mean quality of life scores before the intervention and after the intervention was $(10,54 \pm 8,30)$ and there was an effect of self- efficacy training on the quality of life of cancer patients undergoing chemotherapy with a $p$ value of $0,000<0,05$.

Structured self-efficacy training can build self-efficacy slowly and thoroughly in improving aspects of quality of life (Tsay, 2003). Self-efficacy training for cancer patients undergoing chemotherapy will provide an opportunity for the individual to build and increase his confidence to deal with things in the future that must be endured. A strong self-confidence will be able to change the overall quality of life of a person both physical condition, social/family relationship, feeling condition and functional condition.

The results of the study illustrated the difference in mean quality of life scores after the intervention and after 4 weeks of intervention by $(6,35 \pm 5,43)$ and there was an effect of self-efficacy training on the quality of life of cancer patients undergoing chemotherapy after 4 weeks of intervention with $\mathrm{p}$ value $0,000<0,05$. The study results showed a significant difference between the three measurements of quality of life both before, after and 4 weeks after the intervention with $\mathrm{p}$ value $0,000<0,05$.

Training in the form of short-term intervention group support in cancer patients can increase self-confidence in overcoming problems and quality of life (Weis, 2003; Ko \& Park, 2011). When health workers assess and implement efficacy based patient health improvement programs are important concepts in shaping the quality of life of patients (Church, 2004; Lu et al., 2017). In this study, it can be concluded that structured self-efficacy training in a short time can be an effort to improve self-efficacy and quality of life in cancer patients undergoing chemotherapy.

\section{Acknowledgments}

The research was sponsored by Polytechnic of Health, Medan, North Sumatera, Indonesia. We would like to thank to health officers at Dr. Pirngadi General Hospital Medan who where care in assist researcher to facilitate the respondents.

\section{Competing Interests Statement}

The authors declare that there are no competing or potential conflicts of interest.

\section{References}

Akin, S., Can, G., Durna, Z., \& Aydiner, A. (2008). The Quality of Life and Self-Efficacy of Turkish Breast Cancer Patients Undergoing Chemotherapy. European Journal of Oncology Nursing, 12(5), 449-456, https://doi.org//10.1016/j.ejon.2008.07.006

$\mathrm{Hu}, \mathrm{A}$. (2017). Reflections: the value of patient support groups. Otolaryngology-Head and Neck Surgery, 156(4), 587-588. https://doi.org/10.1177/0194599817697030

American Cancer Society. (2017). Cancer Facts \& Figures, accessed 31 October 2018

Arruebo, M., Vilaboa, N., Sáez-Gutierrez, B., Lambea, J., Tres, A., Valladares, M., \& González-Fernández, Á. (2011). Assessment of the evolution of cancer treatment therapies. Cancers, 3(3), 3279-3330. https://doi.org/10.3390/cancers3033279

Bronner, M. B., Nguyen, M. H., Smets, E. M., van de Ven, A. W., \& van Weert, J. C. (2018). Anxiety during cancer diagnosis: Examining the influence of monitoring coping style and treatment plan. Psycho-oncology, 27(2), 661-667. https://doi.org/10.1002/pon.4560

Church, M. C. (2004). The Conceptual and Operational Definition of Quality of Life: Systematic Review of The Literature (Thesis, Graduates Studies of Texas A\&M University).

Chirico, A., D'aiuto, G., Penon, A., Mallia, L., De Laurentiis, M., Lucidi, F., ... \& Giordano, A. (2017). Self-efficacy for coping with cancer enhances the effect of reiki treatments during the pre-surgery phase of breast cancer patients. Anticancer research, 37(7), 3657-3665. https://doi.org/10.21873/anticanres.11736

Cunningham, A. J., Lockwood, G. A., \& Cunningham, J. A. (1991). A relationship between perceived self-efficacy and quality of life in cancer patients. Patient Education and Counseling, 17(1), 71-78. 
https://doi.org/10.1016/0738-3991(91)90052-7

Curtis, R., Groarke, A., \& Sullivan, F. (2014). Stress and self-efficacy predict psychological adjustment at diagnosis of prostate cancer. Scientific reports, 4(1), 1-5. https://doi.org/10.1038/srep05569

Dfarhud, D., Malmir, M., \& Khanahmadi, M. (2014). Happiness \& health: the biological factors-systematic review Article. Iranian journal of public health, 43(11), 1468.

Driessen, C. M. L., de Kleine-Bolt, K. M. E., Vingerhoets, A. J. J. M., Mols, F., \& Vreugdenhil, G. (2012). Assessing the impact of chemotherapy-induced peripheral neurotoxicity on the quality of life of cancer patients. Supportive care in cancer, 20(4), 877-881. https://doi.org/10.1007/s00520-011-1336-0

Foster, C., Breckons, M., Cotterell, P., Barbosa, D., Calman, L., Corner, J., ... \& Smith, P. W. (2015). Cancer survivors' self-efficacy to self-manage in the year following primary treatment. Journal of Cancer Survivorship, 9(1), 11-19. https://doi.org/10.1007/s11764-014-0384-0

Harrington, S. E., \& Smith, T. J. (2008). The role of chemotherapy at the end of life:"when is enough, enough?". Jama, 299(22), 2667-2678. https://doi.org/10.1001/jama.299.22.2667

Hoffman, A. J. (2013). Enhancing self-efficacy for optimized patient outcomes through the theory of symptom self-management. Cancer nursing, 36(1), E16. https://doi.org/10.1097/NCC.0b013e31824a730a

Iconomou, G., Mega, V., Koutras, A., Iconomou, A. V., \& Kalofonos, H. P. (2004). Prospective assessment of emotional distress, cognitive function, and quality of life in patients with cancer treated with chemotherapy. Cancer, 101(2), 404-411. https://doi.org/10.1002/cncr.20385

Juczyński, Z. (2006). Health-Related Guality of Life: Theory and Measurement. Acta Universitatis Lodziensis. Folia Psychologica, 10.

Junaidi, I. (2007). Kanker. Jakarta: Bhuana Ilmu

Ko, H. K., \& Park, G. J. (2011). Effects of self-efficacy promotion program on self-efficacy, self-care behavior, and quality of life in breast cancer patients receiving radiotherapy. Journal of Korean Oncology Nursing, 11(2), 136-146. https://doi.org/10.5388/jkon.2011.11.2.136

Lavdaniti, M. (2015). Assessment of symptoms in cancer patients undergoing chemotherapy in Northern Greece. Materia socio-medica, 27(4), 255. https://doi.org/10.5455/msm.2015.27.255-258

Leigh, S. A., \& Stovall, E. L. (2012). Quality of Life. From Nursing and Patient Perspectives.Theory. Research Practice (3rd Edition) Canada : Jones\&Barlett Learning

Lev, E. L., Paul, D., \& Owen, S. V. (1999). Age, self-efficacy, and change in patients' adjustment to cancer. Cancer practice, 7(4), 170-176. https://doi.org/10.1046/j.1523-5394.1999.74004.X

Lu, J., Zeng, X., Liao, J., Zhang, Y., Yang, L., Li, Y., \& Lv, J. (2017). Effectiveness of an intervention to promote self-efficacy on quality of Life of patients with nasopharyngeal carcinoma of the Zhuang Tribe Minority in Guangxi, China: A prospective study. Medical science monitor: international medical journal of experimental and clinical research, 23, 4077. https://doi.org/10.12659/MSM.903205

Massoni, F., Ricci, L., Pelosi, M., \& Ricci, S. (2015). Quality of Life in Chemotherapy. Edorium J Disabil Rehabil, 1, 9-11, https://doi.org//10.5348/D05-2015-2-LE-2

Zhang, M., Peng, L., Liu, W., Wen, Y., Wu, X., Zheng, M., ... \& Chan, S. (2015). Physical and psychological predictors of quality of life in Chinese colorectal cancer patients during chemotherapy. Cancer nursing, 38(4), 312-321. https://doi.org/10.1097/NCC.0000000000000190

Mystakidou, K., Tsilika, E., Parpa, E., Gogou, P., Panagiotou, I., Vassiliou, I., \& Gouliamos, A. (2013). Relationship of general self-efficacy with anxiety, symptom severity and quality of life in cancer patients before and after radiotherapy treatment. Psycho-Oncology, 22(5), 1089-1095.

Nayak, M. G., George, A., Vidyasagar, M. S., Mathew, S., Nayak, S., Nayak, B. S., ... \& Kamath, A. (2017). Quality of life among cancer patients. Indian journal of palliative care, 23(4), 445. https://doi.org/10.4103/IJPC.IJPC_82_17

Omran, S., \& Mcmillan, S. (2018). Symptom severity, anxiety, depression, self-efficacy and quality of life in patients with cancer. Asian Pacific journal of cancer prevention: APJCP, 19(2), 365.

Perwitasari, D. A. (2009). Pengukuran Kualitas Hidup Pasien Kanker Sebelum dan Sesudah Kemoterapi dengan EORTC QLQ-C30 di RSUP Dr.Sardjito Yogyakarta. Majalah Farmasi Indonesia, 20(2), 68-72 
Snyder, C. R., \& Lopez, S. J. (Eds.). (2001). Handbook of positive psychology. Oxford university press.

Tsay, S. L. (2003). Self-efficacy training for patients with end-stage renal disease. Journal of advanced nursing, 43(4), 370-375. https://doi.org/10.1046/j.1365-2648.2003.02725.x

Weis, J. (2003). Support Groups For Cancer Patients. Supportive Care In Cancer, 11(12), 763-768, Springer-Verlag. https://doi.org//10.1007/s00520-003-0536-7

WHO. (2018). Cancer. Downloaded on 31 October 2018.

WHO. (2008). The Right to Health, Switzerland : United Nations

Williams, D. M., \& Rhodes, R. E. (2016). The confounded self-efficacy construct: Conceptual analysis and recommendations for future research. Health psychology review, 10(2), 113-128. https://doi.org/10.1080/17437199.2014.941998

\section{Copyrights}

Copyright for this article is retained by the author(s), with first publication rights granted to the journal.

This is an open-access article distributed under the terms and conditions of the Creative Commons Attribution license (http://creativecommons.org/licenses/by/4.0/). 